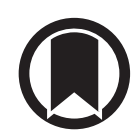

CrossMark

\section{The Mechanical Ventilation-Respiratory Distress Observation Scale as a surrogate of self-reported dyspnoea in intubated patients}

To the Editor:

Intensive care unit (ICU) patients are exposed to many sources of discomfort, among which dyspnoea is one of the more severely distressing [1]. In invasively mechanically ventilated patients, dyspnoea is frequent $(47 \%$ of intubated patients report breathing discomfort when they can first communicate with caregivers) and severe (median rating of 5 on a dyspnoea visual analogue scale (D-VAS); association with anxiety and neurovegetative signs of stress) [2]. It is often linked to ventilator settings and seems to be associated with poorer clinical outcomes (e.g. delayed extubation and post-traumatic stress disorders) [2, 3]. As in other settings, identifying and quantifying dyspnoea in mechanically ventilated patients is therefore a major clinical issue. This is challenging because self-report and self-assessment, prerequisites for D-VAS assessment [4], are often impossible or very difficult in this setting. Unfortunately, caregivers markedly underestimate dyspnoea in this context $[5,6]$. The risk of occult respiratory suffering is therefore major in the ICU setting and neglecting it would amount to medical error [7].

Observation scales incorporating physical and behavioural signs have been developed and validated as surrogates for self-reported dyspnoea in palliative care [8]. Recently, we validated the Intensive CareRespiratory Distress Observation Scale (IC-RDOS) [9], a five-item scale tailored to best correlate with D-VAS in communicative ICU patients (heart rate, neck muscle use during inspiration, abdominal paradox, facial expression of fear and supplemental oxygen). IC-RDOS is also promising in noncommunicative ICU patients [10] but it is not fully adapted to an intubated population because of the "supplemental oxygen" item that will almost always be present in intubated patients. The aim of the present study was to develop a dyspnoea observation scale suitable for mechanically ventilated and intubated patients, and to evaluate its performance.

For this purpose, we carried out an ancillary analysis of the data prospectively collected from 220 unselected communicative ICU patients (31 (15\%) invasively mechanically ventilated patients) enrolled for the validation of the IC-RDOS [9].

Statistical analyses used are described in the IC-RDOS study methods [9]. To move from IC-RDOS to the Mechanical Ventilation-Respiratory Distress Observation Scale (MV-RDOS), we first removed "supplemental oxygen" from the selected items. This gave a four-item correlate of D-VAS ( $r=0.47,95 \%$ CI $0.32-0.60 ; \mathrm{p}<0.0001)$ of which a 2.2 value predicted a D-VAS $>3$ with $48.1 \%$ sensitivity and a $93.9 \%$ specificity (area under the curve (AUC) 0.763 , 95\% CI 0.679-0.848). To improve these performances, we then added the item "respiratory rate" to the four remaining items. We chose respiratory rate because of an initial modest but significant correlation with D-VAS (Spearman's $r=0.262$, 95\% CI 0.09-0.42; $\mathrm{p}=0.004$ ) and because of its contribution to the third factorial dimension of the principal component analysis. This choice was also guided by the clinical knowledge that therapeutic interventions aimed at improving patients' comfort under mechanical ventilation tend to slow down respiratory rate (e.g. optimisation of ventilator settings or the administration of opiates). We hypothesised that the presence of a "respiratory rate" item in MV-RDOS would make its responsiveness to interventions more likely.

@ERSpublications

Dyspnoea assessment is challenging in intubated patients. The Mechanical Ventilation-Respiratory Distress Observation Scale could be of major clinical relevance, making breathing comfort evaluation possible in critically ill, noncommunicative patients. http://ow.ly/nhwx30lL13Q

Cite this article as: Decavèle M, Gay F, Persichini R, et al. The Mechanical Ventilation-Respiratory Distress Observation Scale as a surrogate of self-reported dyspnoea in intubated patients. Eur Respir J 2018; 52: 1800598 [https://doi.org/10.1183/13993003.00598-2018]. 


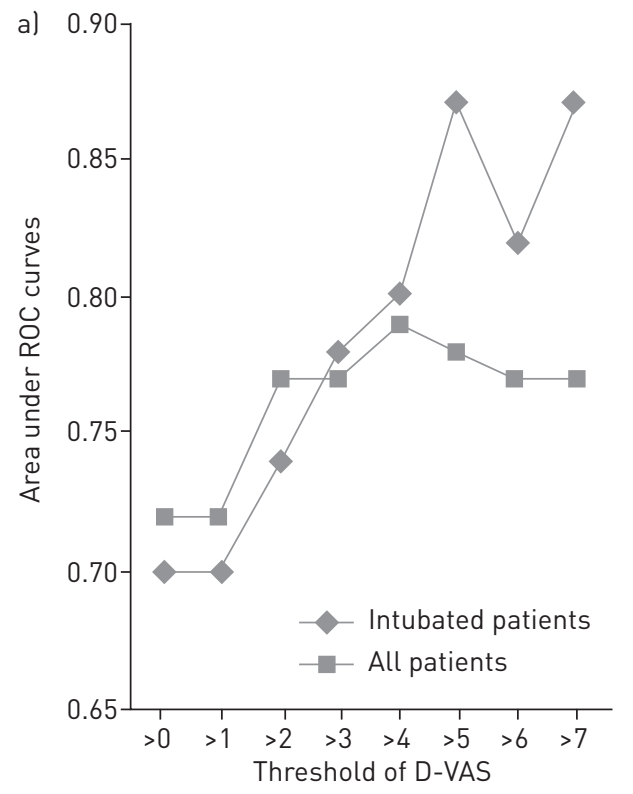

b)

\begin{tabular}{lc}
\hline Variables & Score \\
\hline 0$)$ & 3.3 \\
1) HR beats per min & $+\mathrm{HR} / 65$ \\
$\begin{array}{lc}\text { 2) Use of neck muscles during inspiration } \\
\quad \text { If present }\end{array}$ & +1 \\
$\quad$ If absent & -1
\end{tabular}

3) Abdominal paradox during inspiration If present

If absent

4) Facial expression of fear If present

If absent

5) RR cycles per min

FIGURE 1 a) Comparison of the areas under the receiver operating characteristic (ROC) curves for the Mechanical Ventilation-Respiratory Distress Observation Scale (MV-RDOS) according to the dyspnoea visual analogue scale (D-VAS) thresholds between intubated patients and the whole cohort. b) Calculation of the MV-RDOS. HR: heart rate; RR: respiratory rate.

Iterations were performed to determine weighting factors that optimised the model. This led to a maximal Spearman's r-value of 0.47 (95\% CI 0.36-0.57; $\mathrm{p}<0.001)$ with MV-RDOS=3.3+(heart rate/65)+(respiratory rate $/ 50)+\mathrm{IF}($ paradox breathing $=0,-1,1)+\mathrm{IF}$ (accessory muscles $=0,-1,1)+\mathrm{IF}($ fear $=0,-1,1)$. This model was simplified into MV-RDOS=3.3+(heart rate/65)+(respiratory rate/50)+(1×paradox breathing $)+(1 \times$ accessory muscles $)+(1 \times$ Fear) (figure 1$)$. A MV-RDOS of 2.3 predicted a D-VAS $>3$ with $72 \%$ sensitivity and a $74 \%$ specificity (AUC $0.769,95 \%$ CI 0.690-0.849), which was slightly better than the four-item IC-RDOS.

Finally, because the MV-RDOS is thought to be more applicable for intubated patients, we also tested its performance in the subgroup of 31 intubated patients. Figure 1 shows the receiver operating characteristic AUCs for the MV-RDOS according to the D-VAS thresholds in intubated patients and the whole cohort. Among intubated patients, a MV-RDOS of 2.6 predicted a D-VAS $>3$ with $57 \%$ sensitivity and a $94 \%$ specificity, with an AUC of 0.782 (95\% CI 0.581-0.982). The ability of the MV-RDOS to detect significant dyspnoea (D-VAS $>3$ ) is likely to be better among intubated patient than in the whole cohort (figure 1).

Critically ill intubated patients are more likely to be exposed to risk factors of dyspnoea than nonintubated patients. Moreover, they may equally exhibit clinical and behavioural signs of respiratory discomfort [10], which can be compiled in scoring systems used as surrogates of D-VAS [8-10]. However, this heteroevaluation approach to dyspnoea in the ICU setting reveals its full usefulness among intubated patients in whom self-report and self-assessment are impossible or very difficult. Our results suggest that MV-RDOS could be of value to identify intubated ICU patients experiencing dyspnoea or highly suspected of suffering from it, regardless of their self-report abilities. They pave the way for clinical validation studies among intubated patient (exclusively) who will have to assess the feasibility of MV-RDOS in clinical practice and above all its responsiveness to therapeutic interventions aimed at reducing dyspnoea. It will never be possible to be certain that a noncommunicative intubated patient actually suffers from dyspnoea because clinical or neurophysiological surrogates will never replace self-report. However, the poor ability of caregivers to adequately identify dyspnoea in intubated patients $[5,6]$ indicates that there is an unmet need for tools allowing caregivers to at least suspect that a patient might be suffering from dyspnoea. Such tools would probably be of major clinical relevance if, for example, they prompted a clinical checklist aimed at identifying factors known to induce dyspnoea and that are often simple to correct, including suboptimal ventilator settings [2]. We believe that MV-RDOS could be such a tool.

Maxens Decavèle ${ }^{1,2}$, Frédérick Gay ${ }^{3}$, Romain Persichini ${ }^{1,2}$, Julien Mayaux ${ }^{2}$, Capucine Morélot-Panzini ${ }^{1,2}$, Thomas Similowski ${ }^{1,2}$ and Alexandre Demoule ${ }^{1,2}$

${ }^{1}$ Sorbonne Université, INSERM, UMRS1158 Neurophysiologie Respiratoire Expérimentale et Clinique, Paris, France. ${ }^{2}$ AP-HP, Groupe Hospitalier Pitié-Salpêtrière Charles Foix, Service de Pneumologie et Réanimation Médicale du Département R3S, Paris, France. ${ }^{3}$ AP-HP, Groupe Hospitalier Pitié-Salpêtrière-Charles Foix, Pôle Biologie Médicale et Pathologie, Service de Parasitologie et Mycologie, Paris, France. 
Correspondence: Alexandre Demoule, Dept of Respiratory and Critical Care Medicine, Groupe Hospitalier PitiéSalpêtrière, 47-83 Boulevard de l'Hôpital, 75013 Paris, France. E-mail: alexandre.demoule@aphp.fr

Received: March 272018 | Accepted after revision: Aug 312018

Author contributions: M. Decavèle, F. Gay, R. Persichini, C. Morélot-Panzini, T. Similowski and A. Demoule conceived and designed the study. R. Persichini, J. Mayaux, A. Demoule and F. Gay acquired the data. M. Decavèle, F. Gay, R. Persichini, C. Morélot-Panzini, T. Similowski and A. Demoule analysed and interprested the data. M. Decavèle, F. Gay, T. Similowski and A. Demoule drafted the manuscript. M. Decavèle, F. Gay, R. Persichini, C. Morélot-Panzini, T. Similowski and A. Demoule gave final approval to submission.

Conflict of interest: M. Decavèle has nothing to disclose. F. Gay has nothing to disclose. R. Persichini has nothing to disclose. J. Mayaux has nothing to disclose. C. Morelot-Panzini has nothing to disclose. T. Similowski reports receiving personal fees from AstraZeneca, Invacare, Chiesi, Lungpacer Inc., TEVA, Novartis, GSK and Boerhinger Ingelheim France, outside the submitted work; in addition, he has a patent on a brain-ventilator interface licensed to Air Liquide Medical Systems and MyBrainTechnology, and pending patents on a protection device for intubation pending and a noncontact thoracic movement imaging system. A. Demoule reports research contracts with Philips, and personal fees from Medtronic, Fisher and Paykel and Baxter, outside the submitted work.

Support statement: This study was supported by Association pour le Développement et l'Organisation de la Recherche en Pneumologie et sur le Sommeil, Paris, France, and by the programme Investissement d'Avenir ANR-10-AIHU 06 of the French Government. Funding information for this article has been deposited with the Crossref Funder Registry.

\section{References}

1 Chanques G, Nelson J, Puntillo K. Five patient symptoms that you should evaluate every day. Intensive Care Med 2015; 41: 1347-1350.

2 Schmidt M, Demoule A, Polito A, et al. Dyspnea in mechanically ventilated critically ill patients. Crit Care Med 2011; 39: 2059-2065.

3 Cuthbertson $\mathrm{BH}$, Hull A, Strachan $\mathrm{M}$, et al. Post-traumatic stress disorder after critical illness requiring general intensive care. Intensive Care Med 2004; 30: 450-455.

4 Parshall MB, Schwartzstein RM, Adams L, et al. An official American Thoracic Society statement: update on the mechanisms, assessment, and management of dyspnea. Am J Respir Crit Care Med 2012; 185: 435-452.

5 Haugdahl HS, Storli SL, Meland B, et al. Underestimation of patient breathlessness by nurses and physicians during a spontaneous breathing trial. Am J Respir Crit Care Med 2015; 192: 1440-1448.

6 Binks AP, Desjardin S, Riker R. ICU clinicians underestimate breathing discomfort in ventilated subjects. Respir Care 2017; 62: 150-155.

7 Başoğlu M. Effective management of breathlessness: a review of potential human rights issues. Eur Respir J 2017; 49: 1602099.

8 Campbell ML, Templin T, Walch J. A respiratory distress observation scale for patients unable to self-report dyspnea. J Palliat Med 2010; 13: 285-290.

9 Persichini R, Gay F, Schmidt M, et al. Diagnostic accuracy of respiratory distress observation scales as surrogates of dyspnea self-report in intensive care unit patients. Anesthesiology 2015; 123: 830-837.

10 Demoule A, Persichini $R$, Decavèle $M$, et al. Observation scales to suspect dyspnea in non-communicative intensive care unit patients. Intensive Care Med 2018; 44: 118-120. 